\title{
Study of Structure and Properties of Fe-Based Amorphous Ribbons after Pulsed Laser Interference Heating
}

\author{
Olaf Czyż, Jan Kusiński, Agnieszka Radziszewska, Zhongquan Liao, Ehrenfried Zschech, Małgorzata Kạc, and Roman Ostrowski
}

\author{
(Submitted August 29, 2019; in revised form August 25, 2020; published online September 15, 2020)
}

\begin{abstract}
The paper is devoted to the study of microstructural and magnetic properties of the Fe-based amorphous ribbons after interference pulsed laser heating. The ternary amorphous alloy FeSiB, as well as the multicomponent alloys $\mathrm{FeCuSiB}$ and $\mathrm{FeCuNbSiB}$, was subjected to laser pulses to induce crystallization in many microislands simultaneously. Structure and properties changes occurred in laser-heated dots. Detailed TEM analysis from a single dot shows the presence of $\mathrm{FeSi}(\alpha)$ nanocrystals in the amorphous matrix. The FeSiB alloy is characterized after conventional crystallization by a dendritic structure; however, the alloys with copper as well copper and niobium additions are characterized by the formation of equiaxed crystals in the amorphous matrix. Amorphous alloys before and after the laser heating are soft magnetic; however, conventional crystallization leads to a deterioration of the soft magnetic properties of the material.
\end{abstract}

Keywords FeSiB, HRTEM, magnetic properties, microstructure

\section{Introduction}

Fe-based amorphous alloys have been extensively studied due to their very soft magnetic properties such as high saturation magnetization and near-zero coercivity (Ref 1-3). Due to their soft magnetic properties, these materials are used in production of magnetic cores, wires and shields. Since the amorphous structure of metallic glasses is metastable, crystallization processes of these alloys have been reported in many papers. It has been proved that the soft magnetic properties and the saturation magnetization of Fe-based amorphous materials can be improved by nanocrystallization of these materials (Ref $4,5)$. The best magnetic properties have been shown for alloys

This article is an invited submission to JMEP selected from presentations at The XXII Physical Metallurgy and Materials Science Conference: Advanced Materials and Technologies (AMT 2019) held June 9-12, 2019, in Bukowina Tatrzańska, Poland, and has been expanded from the original presentation.

Olaf Czyż, Jan Kusiński, and Agnieszka Radziszewska, Faculty of Metals Engineering and Industrial Computer Science, AGH University of Science and Technology, Al. Mickiewicza 30, 30-059 Kraków, Poland; Zhongquan Liao and Ehrenfried Zschech, Microelectronic Materials and Nanoanalysis, Fraunhofer Institute for Ceramic Technologies and Systems, Maria-Reiche-Str. 2, 01109 Dresden, Germany; Malgorzata Kacc, Institute of Nuclear Physics, 152 Radzikowskiego Str., 31342 Kraków, Poland; and Roman Ostrowski, Institute of Optoelectronics, Military University of Technology, 2 Gen. S. Kaliskiego Str., 00-908 Warsaw, Poland. Contact e-mails: olafczyz@agh.edu.pl, kusinski@agh.edu.pl, Agnieszka.Radziszewska@ agh.edu.pl, zhongquan.liao@ikts.fraunhofer.de, ehrenfried.zschech@ ikts.fraunhofer.de, Malgorzata.Kac@ifj.edu.pl, and roman.ostrowski@ wat.edu.pl. with nanometer size of grains $(\operatorname{Ref} 1,4,6)$. That means, since a growing grain size leads to a deterioration of soft magnetic properties, the goal is to produce nanocrystalline alloys (Ref 6). Unfortunately, the traditional heat treatment of FeSiB alloys leads to micrometer size of dendrites (Ref 3 ). On the other hand, annealing lead softens to a decrease in hardness and Young's modulus, and consequently in a brittle crystalline state that makes the handling of the samples difficult (Ref 7). A proper heat treatment that leads to nanocrystallization is difficult to achieve due to the simultaneous formation and growth of a crystalline phase which is characterized by harder magnetic properties than amorphous materials (Ref 8). Several unconventional techniques have been investigated to obtain nanostructured alloys (Ref 9-14). The pulsed laser interference process is based on the interference of at least two laser beams. The laser beams affect and create an interference pattern on the sample surface (Ref 15-17). This process results in periodically arranged laser-heated microislands with changed structure and magnetic properties (Ref 18, 19).

The present study is focused on the microstructure evolution of Fe-based amorphous ribbons after pulsed laser interference heating and crystallization during annealing. The structure after laser and heat treatment is related to the magnetic properties of these alloys.

\section{Experimental Materials and Methods}

Fe-based amorphous alloys $\mathrm{Fe}_{80} \mathrm{Si}_{11} \mathrm{~B}_{9}, \mathrm{Fe}_{77} \mathrm{Cu}_{1} \mathrm{Si}_{13} \mathrm{~B}_{9}$ and $\mathrm{Fe}_{75} \mathrm{Cu}_{1} \mathrm{Nb}_{2} \mathrm{Si}_{1} 3 \mathrm{~B}_{9}$, with a thickness of $30 \mu \mathrm{m}$ and a width of $25 \mathrm{~mm}$ and $10 \mathrm{~mm}$, respectively, were studied. The chemical composition is well known as Metglass and Finemet alloys. Since these alloys are well investigated, it could well describe the influence of PLIH process on the structure and magnetic properties of these alloys. The amorphous alloys were fabricated by melt spinning (Ref 6, 20). Pulsed laser interference heating (PLIH) was performed using a Nd:YAG (12 mm bar) laser with basic wavelength $(1064 \mathrm{~nm}), 8-\mathrm{ns}$ pulse time 
duration and $1 \mathrm{~Hz}$ frequency. The interference pattern was generated by a quartz tetrahedral prism with an apex angle of $172^{\circ}$. The device to perform PLIH process was described in (Ref 21). During the PLIH process, the number of consecutive laser pulses in the same area varied from 50 to 500, with $120 \mathrm{~mJ}$ energy. The laser beam parameters were selected to avoid ablation and cause maximum structure changes. Series of pulsed laser interference heating performed (Ref 19) and $120 \mathrm{~mJ}$ energy provided the most hopeful results. The samples were prepared by further heating the amorphous materials to $873 \mathrm{~K}$ at a rate of $20 \mathrm{~K} / \mathrm{min}$ and slow cooling down to room temperature. Phase transformation of amorphous ribbon was tested using differential scanning calorimetry (DSC 800 Perkin Elmer) in a nitrogen atmosphere with $20 \mathrm{~K} / \mathrm{min}$ heating rate. The structure of amorphous, laser-heated and annealed samples was studied using scanning (SEM-FEI Inspect S50) and transmission electron microscopy (TEM-Jeol JEM 2010ARP). A Zeiss Libra 200 MC Cs STEM was used for structure characterization. The TEM samples were prepared by electropolishing of disks, cut from plain view. The magnetic properties were described by magnetic hysteresis loop measurements using a superconducting quantum interference device: (SQUID) magnetometer Quantum Design, MPMS, by applying an external field up to $4 \mathrm{~T}$. The magnetic moment was determined with accuracy of $2 \%$ or better. The samples for SQUID measurements were cut as 3-mm disks and weighed to reference magnetization to the sample mass.

\section{Results and Discussion}

\subsection{Phase Transformation}

The DSC measurement of as-cast FeSiB amorphous ribbon indicates the presence of two exothermic peaks (Fig. 1): First at $785 \mathrm{~K}$ (onset $775 \mathrm{~K}$ ) was observed crystallization by the formation of primary $\mathrm{BCC} \alpha-\mathrm{Fe}(\mathrm{Si})$ phase, and second at $831 \mathrm{~K}$ (onset $825 \mathrm{~K}$ ) it corresponds to the precipitation of intermetallic phases like $\mathrm{Fe}-\mathrm{B}$. It has been reported that at about $831 \mathrm{~K}, \mathrm{Fe}_{3} \mathrm{~B}$ intermetallic phase is formed (Ref 2,22$)$. It has been reported that copper addition decreases primary crystallization temperature (Ref 23). The alloys with copper and niobium addition were characterized by higher primary crystallization temperature (Ref 24). The temperature of crystallization by annealing was selected $40 \mathrm{~K}$ above the peak of the precipitation intermetallic phase. Reason of this was crystallization after completed phase transformations.

\subsection{Microstructure}

Scanning electron microscopy (SEM) images showed a twodimensional structure composed of periodically arranged microislands fabricated by laser (Fig. 2). The distance between the microislands was about $16 \mu \mathrm{m}$. An increase in the number of laser pulses applied to the FeSiB alloy melted the surface and caused ablation of material (Fig. 2 and 3). Irradiation with 500 consecutive laser pulses led to the formation of ripples in the laser-heated microislands (Fig. 2d and 3b). According to Jia et al. (Ref 25), the creation of ripples is caused by the interference of the incident laser light and the scattered tangential light. The distance between the ripples is equal to the basic wavelength of Nd:YAG laser beam ( $1064 \mathrm{~nm})($ Ref 18).
Ripples were also observed at the $\mathrm{FeCuSiB}$ sample irradiated with 500 laser pulses (Fig. 3d) and at the FeCuNbSiB alloy after 200 laser pulses (Fig. 3e). The FeCuNbSiB alloy, laser heated with 500 laser pulses, was the alloy with the most heavily damaged surface in the microislands (Fig. 3f). This is probably due to thermophysical changes of alloys caused by $\mathrm{Cu}$ and $\mathrm{Nb}$ additions. Transmission electron microscopy (TEM) of the $\mathrm{FeSiB}$ laser-heated alloy showed nanocrystalline regions in the amorphous matrix (Fig. 4). Selected area electron diffraction (SAED) patterns can be attributed to the [-103] zone axis of $\alpha-\mathrm{Fe}(\mathrm{Si})$. The FeSiB amorphous alloy annealed at $873 \mathrm{~K}$ was characterized by a dendritic structure (Fig. 5a and b), with a variable dendrite size from 100 to $500 \mathrm{~nm}$. The SAED patterns indicate the occurrence of the $\alpha-\mathrm{Fe}(\mathrm{Si})$ structure. Conventional crystallization of $\mathrm{FeCuSiB}$ and $\mathrm{FeCuNbSiB}$ alloys caused single nanocrystals in the amorphous matrix (Fig. 5c, d, e and f). Alloy additions $(\mathrm{Cu}$ and $\mathrm{Nb})$ to $\mathrm{FeSiB}$ alloy resulted in crystal refining during annealing. The FeCuSiB alloy was characterized by crystals of a size from 50 to $100 \mathrm{~nm}$, the $\mathrm{FeCuSiB}$ alloy by about $20 \mathrm{~nm}$ crystals size. As for the ternary alloy, the SAED patterns of these alloys indicate to presence of $\alpha-\mathrm{Fe}(\mathrm{Si})$ structure.

\subsection{High-Resolution Transmission Electron Microscopy}

HRTEM of FeSiB alloys after laser irradiation with $120 \mathrm{~mJ}$ energy and 500 laser pulses showed a [111] $\alpha$-Fe(Si) structure for one single nanocrystal (Fig. 6). At the boundary between the amorphous matrix and the crystals, a partial crystallization of the amorphous material can be observed (Fig. 7). The laser heating of the FeSiB alloy results in the formation of nanometer-sized crystals. The FeSiB sample after conventional crystallization by heating to $873 \mathrm{~K}$ shows a [001] $\alpha$-Fe( $\mathrm{Si})$ structure (Fig. 8). Annealing of this alloy resulted in large crystalline regions. Annealing of the alloy with copper addition led to the creation of $\alpha-\mathrm{Fe}(\mathrm{Si})$ nanocrystals [111] oriented (Fig. 9a, b and c). The matrix was amorphous (Fig. 9d); however, partially crystallized material in the vicinity of crystals was observed (Fig. 9e). The alloy with copper and niobium additions contains the smallest size of nanocrystals. The HRTEM image shows nanocrystals with a size of a few $\mathrm{nm}$ (Fig. 10a). The structure of nanocrystals was $\alpha-\mathrm{Fe}(\mathrm{Si})$ with [111] orientation in the HRTEM (Fig. 10b and c). Annealing of the $\mathrm{FeSiB}$ results in the creation of the highest size of crystals. The smallest size of crystals observed in alloys with copper and niobium addition can be explained according to Yoshizawa by the creation of $\mathrm{Cu}$ and $\mathrm{Nb}$ clusters which becomes nuclei for bcc Fe solid (Ref 1). The Fe grains were surrounded by $\mathrm{Cu}$ and $\mathrm{Nb}$ rich regions, which make grain growth difficult. Different treatments lead to the creation of different structures. The laser heating, as well as the annealing of the FeCuSiB and FeCuNbSiB alloys at $873 \mathrm{~K}$, created nanocrystals in the amorphous matrix. The created structure was $\alpha-\mathrm{Fe}(\mathrm{Si})$ [111] oriented. Conventional crystallization of the base alloy was with a dendritic structure composed of $[001] \alpha-\mathrm{Fe}(\mathrm{Si})$ dendrites. The different orientation of dendrites may be caused by the preferred crystallographic orientation for dendritic growth which is [100] for $\alpha-F e$.

\subsection{Magnetic Properties}

To determine the magnetic properties of materials, magnetic hysteresis loop measurements were carried out. A FeSiB amorphous alloy shows the highest saturation magnetization at 


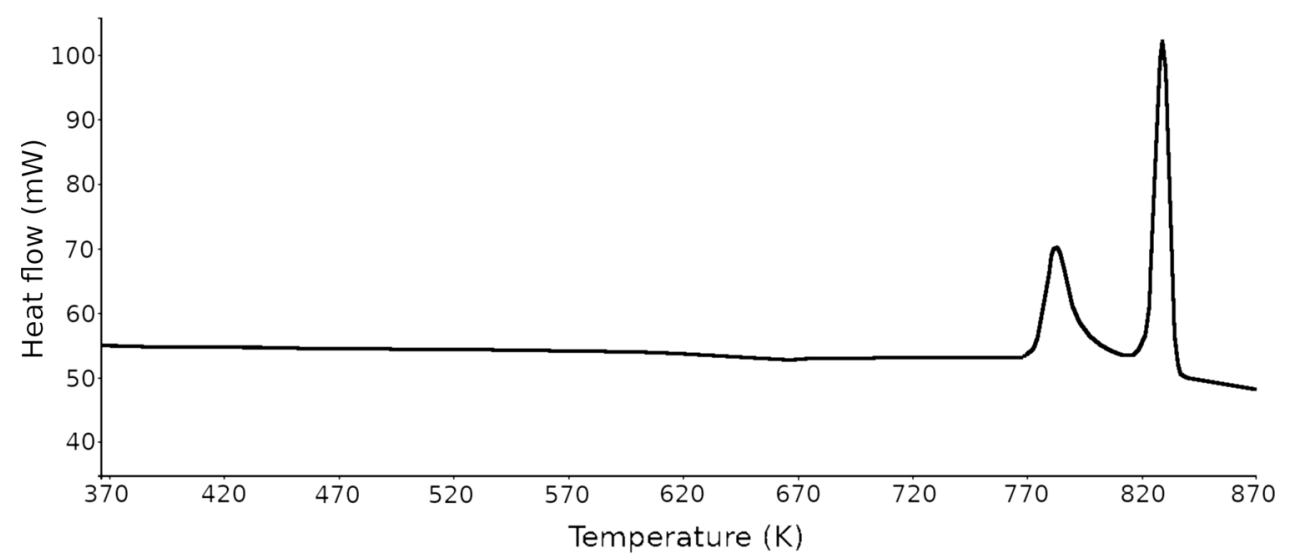

Fig. 1 DSC curve of $\mathrm{FeSiB}$ amorphous ribbon

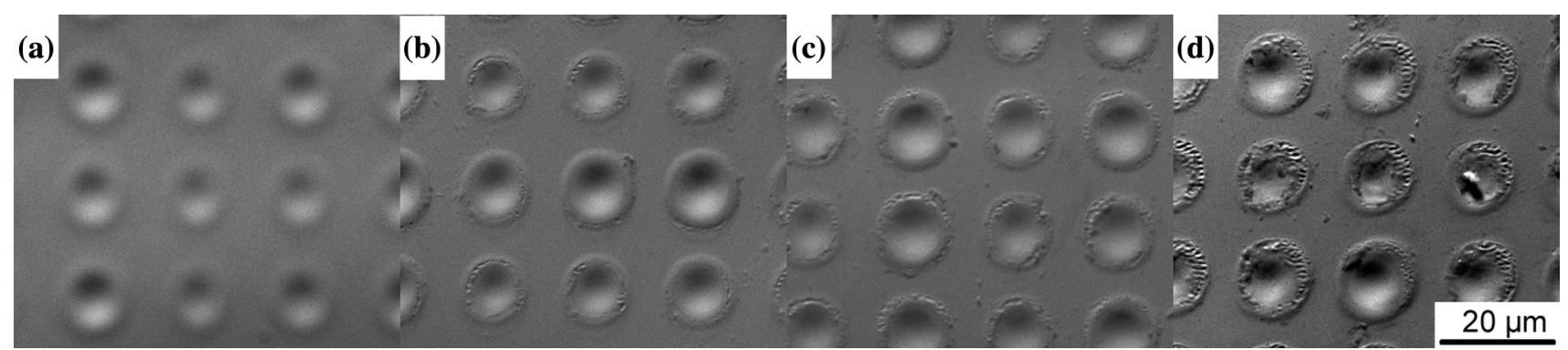

Fig. 2 SEM images of FeSiB alloy after PLIH process with $120 \mathrm{~mJ}$ energy and variable laser pulses: (a) - 100, (b) - 200, (c) - 300, (d) - 500

(a)
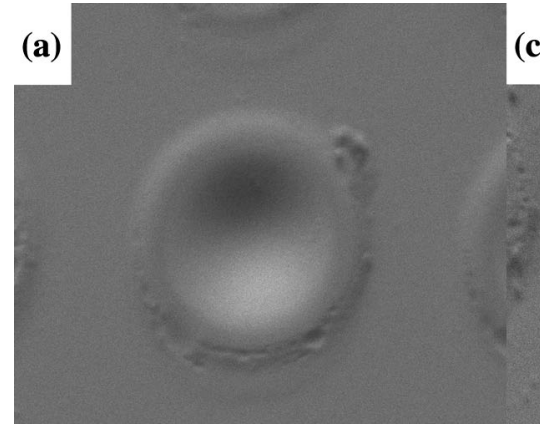

(b)

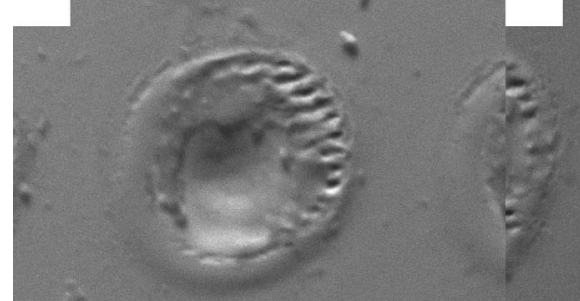

(c)

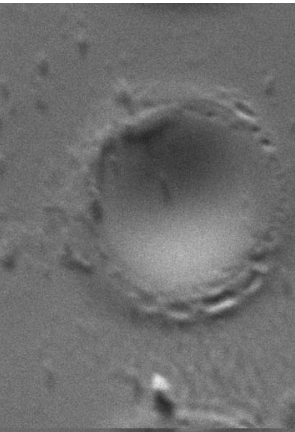

(d)

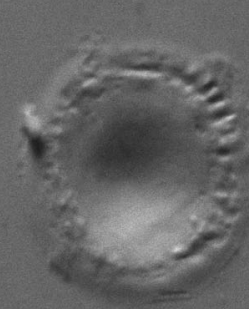

(e)

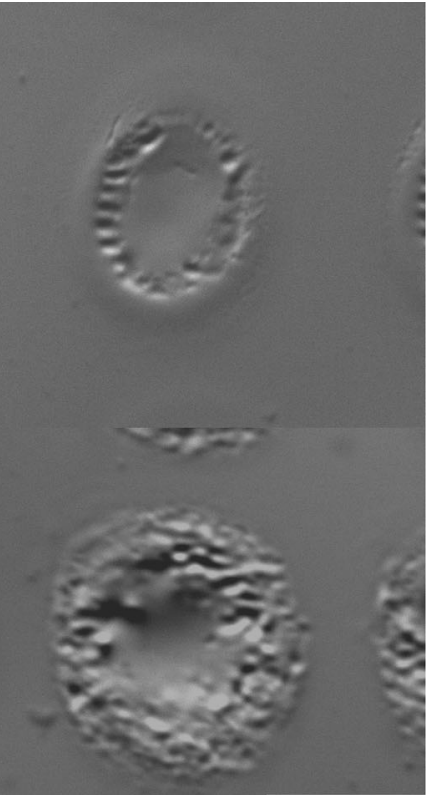

$5 \mu \mathrm{m}$

Fig. 3 SEM images of Fe-based alloys after PLIH process with $120 \mathrm{~mJ}$ energy and variable laser pulses: $\mathrm{FeSiB}$ (a) - 200, (b) - 500, FeCuSiB (c) -200, (d) $-500, \mathrm{FeCuNbSiB}$ (e)-200, (f)-500 


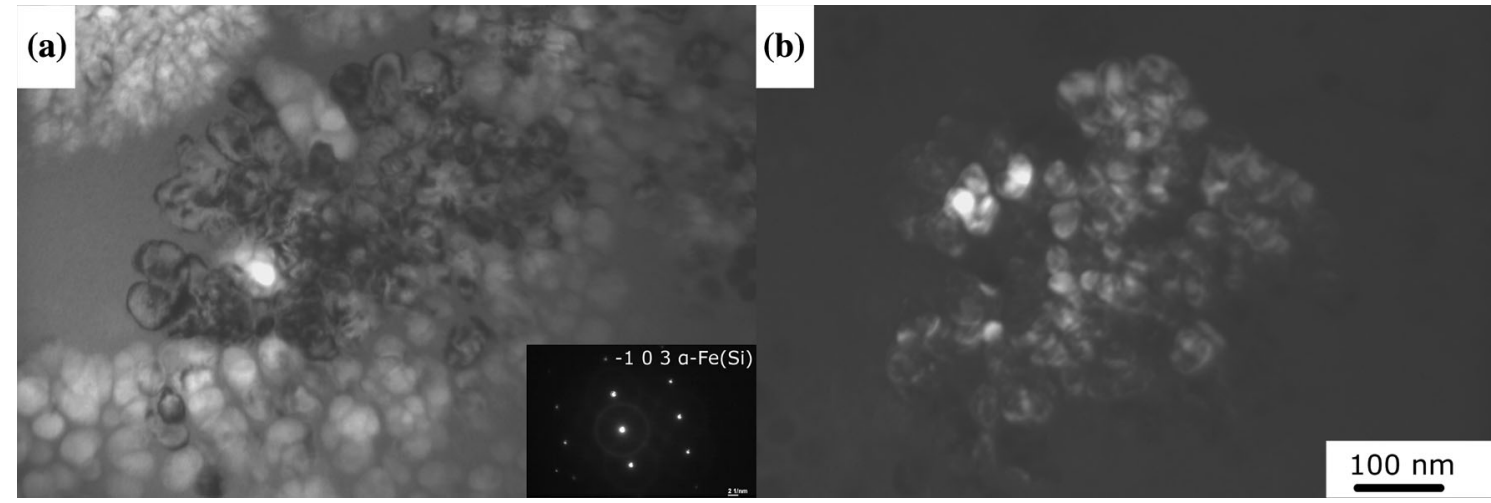

Fig. 4 TEM images of FeSiB alloy after PLIH process with $120 \mathrm{~mJ}$ energy and 500 laser pulses (a)—bright field and SAED, (b) — dark field

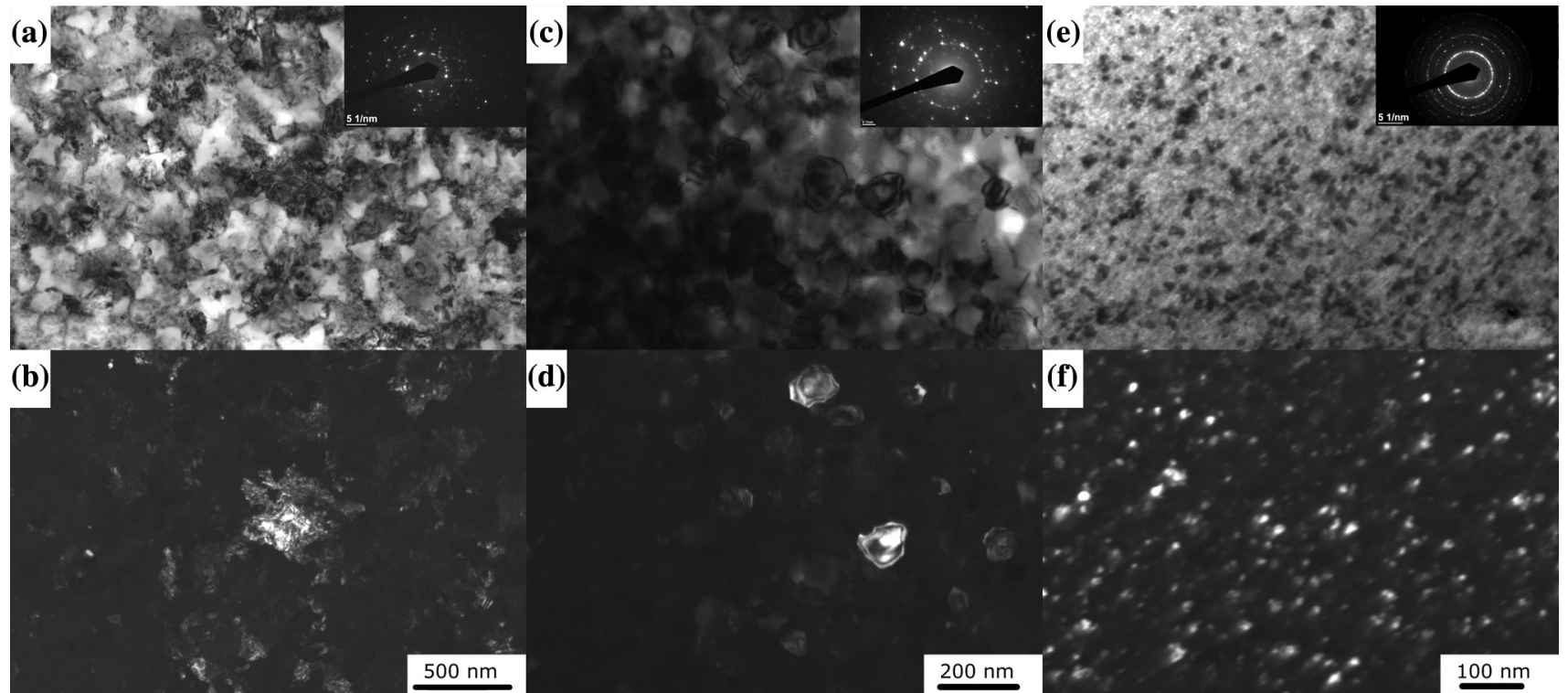

Fig. 5 TEM images of annealed sample at $873 \mathrm{~K}$ : bright field with SAED (a, c, e) and dark field (b, d, f) FeSiB-(a, b) FeCuSiB-(c, d) $\mathrm{FeCuNbSiB}-(\mathrm{e}, \mathrm{f})$

about $1.53 \mathrm{~T}$ (Fig. 11). The FeCuSiB alloy has a $1.36 \mathrm{~T}$ saturation magnetization and the $\mathrm{FeCuNbSiB}$ alloy $1.3 \mathrm{~T}$ (Fig. 11b). The addition of copper and niobium leads to a decreased saturation magnetization of these alloys. Annealing at $873 \mathrm{~K}$ led to a decrease in the saturation magnetization of FeSiB and FeCuSiB alloys. The coercivity of amorphous alloys was $1.5 \mathrm{kA} / \mathrm{m}$. After conventional crystallization, an increase in coercivity to $3 \mathrm{kA} / \mathrm{m}$ was observed. The $\mathrm{FeCuNbSiB}$ alloy after conventional crystallization was characterized by unchanged coercivity (Fig. 11c). The reason for this distinct behavior may be due to crystals' size change; as Herzer (Ref 2) showed, increasing grain size led to increased coercivity of Fe-based nanocrystalline alloys, as observed here for $\mathrm{FeSiB}$ and FeCuSiB alloys. Niobium addition strongly decreases the size of crystals as discussed above: after crystallization, the crystals in FeCuNbSiB alloy were smaller than $20 \mathrm{~nm}$ (Fig. 10). The PLIH process led to a decreased saturation magnetization of these alloys except for the alloy with copper addition (Fig. 12). The FeSiB and the FeCuNbSiB alloys showed a saturation magnetization of $1.45 \mathrm{~T}$ and $1.27 \mathrm{~T}$, respectively, after PLIH with $120 \mathrm{~mJ}$ and 300 laser pulses. The FeCuSiB alloy after laser heating was characterized by a saturation magnetization that was $0.13 \mathrm{~T}$ higher than for the amorphous alloy (Fig. 12b). The coercivity of $1.5 \mathrm{kA} / \mathrm{m}$ was unchanged for these materials after the laser heating process (Fig. 12c).

\section{Conclusions}

The application of the pulsed laser interference heating process formed two-dimensional structures. SEM images showed periodically arranged laser-heated microisland. The crystalline $\alpha-\mathrm{Fe}(\mathrm{Si})$ structures were observed in these microislands. The matrix remained amorphous. HRTEM of the FeSiB alloy after the PLIH process showed single $\alpha$-Fe(Si) nanocrystals and a partially crystallized amorphous matrix. Similar structures were obtained by $\mathrm{Wu}$ et al. (Ref 12) as well as Katakam et al. (Ref 13). It allows concluding that by the focused beams it is possible to obtain nanostructures, but only in laser-heated microisland. The crystallization during anneal- 


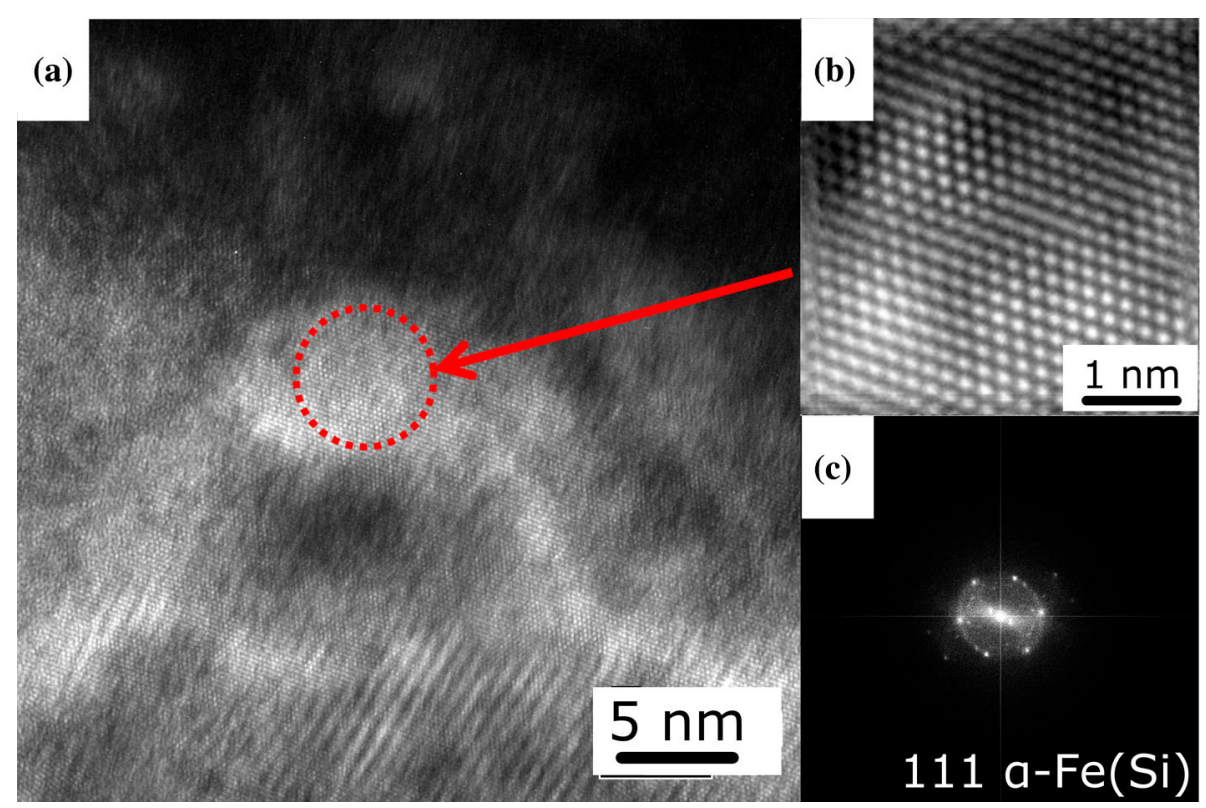

Fig. 6 HRTEM images of FeSiB laser-heated material with $120 \mathrm{~mJ}$ energy and 500 laser pulses: (a)—HRTEM of crystals, (b) —-magnification of selected area, (c) - FFT from 5a image

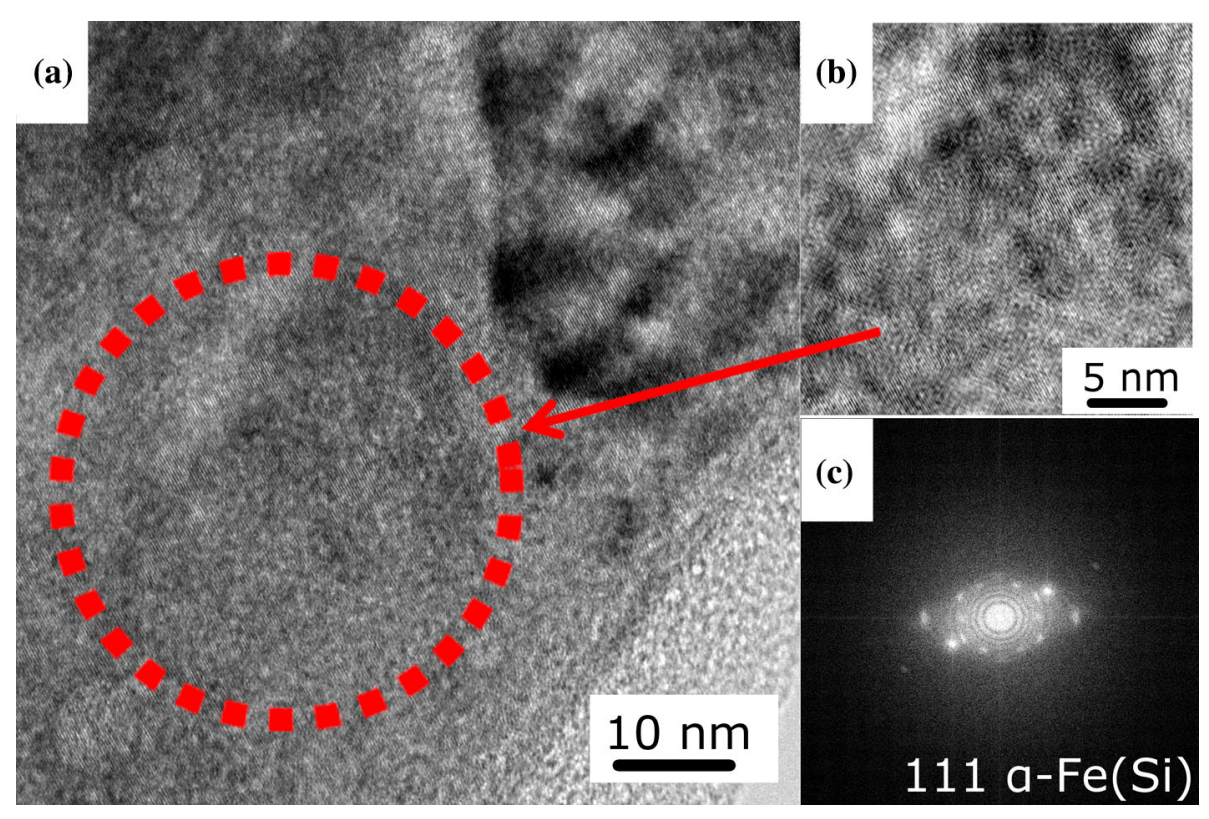

Fig. 7 HRTEM images from boundary between FeSiB laser-heated material with $120 \mathrm{~mJ}$ energy and 500 laser pulses and amorphous matrix: (a) - HRTEM of the amorphous matrix, (b) - magnification of selected area, (c) -FFT from 6a image

ing led to the creation of a dendritic structure of the FeSiB alloy. The dendrites were characterized by a $[001] \alpha-\mathrm{Fe}(\mathrm{Si})$ structure. The FeCuSiB and FeCuNbSiB alloys were characterized by single nanocrystals in the amorphous matrix with different crystal sizes. The alloy with copper addition was characterized by 50 to $100 \mathrm{~nm}$ crystal size and with additional niobium addition by $20 \mathrm{~nm}$ crystal size. Alloying of the ribbons resulted in a [111] $\alpha$-Fe(Si) structure.

The SQUID measurement showed very soft magnetic properties of the amorphous ribbons. The materials that were crystallized during annealing were characterized by a deterio- rated saturation magnetization and coercivity, except for the $\mathrm{FeCuNbSiB}$ alloy. This could be correlated with the structure of these alloys. FeSiB alloy and $\mathrm{FeCuSiB}$ alloy were characterized by coarse dendrite/crystals structure, but FeCuNbSiB alloy had a nanocrystalline structure. The laser heating does not influence to the coercivity of these alloys, but it led to lower saturation magnetization for the FeSiB and FeCuNbSiB alloys. The volume of laser crystallized material must be not enough to increase the soft magnetic properties of these alloys. The FeCuSiB alloy showed higher saturation magnetization after the PLIH process than before the laser heating. Katakam et al. 


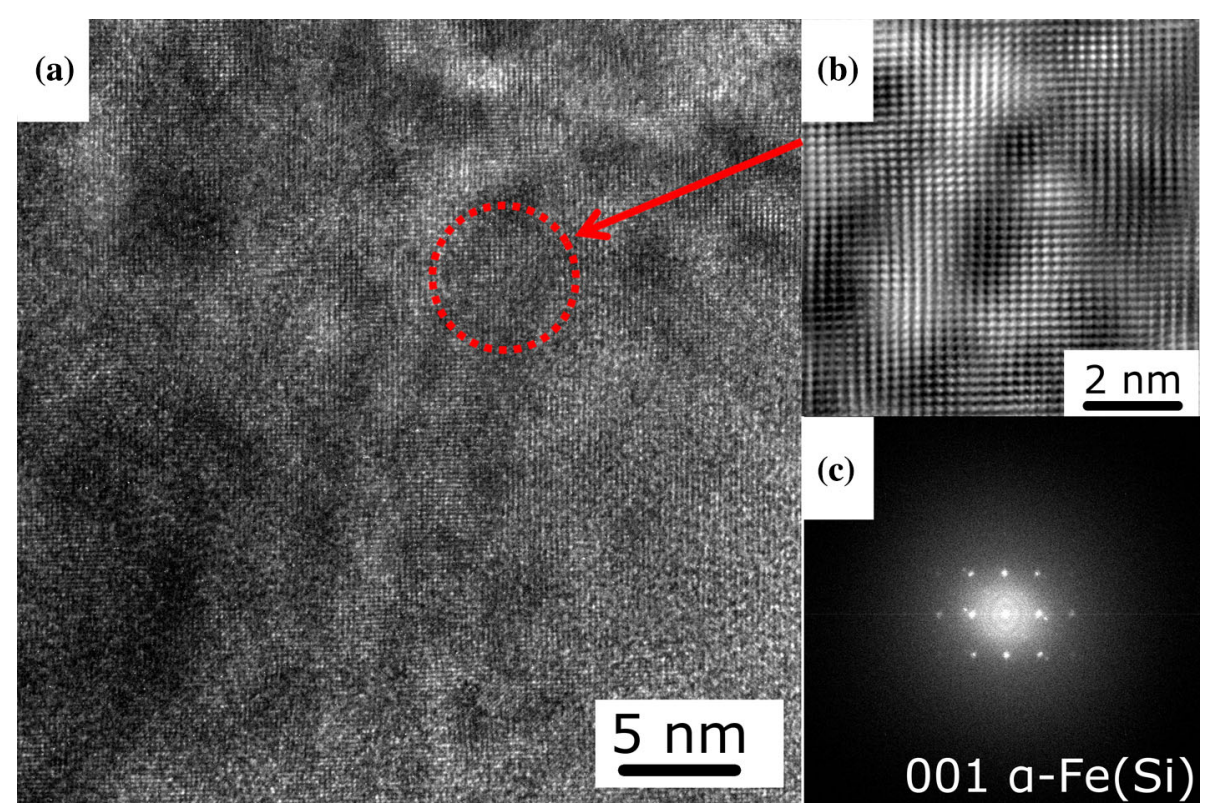

Fig. 8 HRTEM images of FeSiB annealed sample at $873 \mathrm{~K}$ : (a) - HRTEM image, (b) - magnification of selected area, (c) - FFT from 7a image

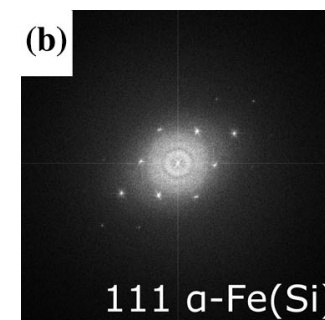

(c)

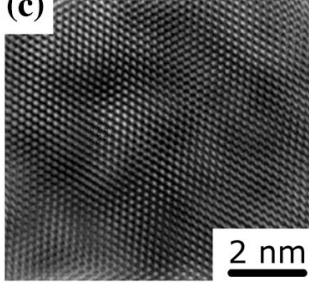

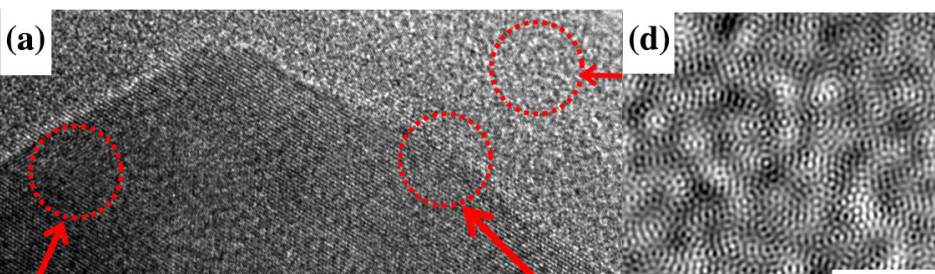

$2 \mathrm{~nm}$ (e)

$\underline{5 \mathrm{~nm}}$

$2 \mathrm{~nm}$

Fig. 9 HRTEM images of FeCuSiB annealed sample at $873 \mathrm{~K}$ : (a)—HRTEM image, (b) —FFT from 8a image, (c, d, e)—magnification of selected areas

(Ref 13) also showed deteriorated coercivity after furnace treatment, but they observed higher saturation magnetization after laser crystallization.

The laser beam energy is delivered at only $8 \mathrm{~ns}$ and is not enough to heat the higher volume of material, so the structural changes are observed only in laser-affected areas. Magnetic properties correlate with a structure so insufficient evolution of the structure will not change the magnetic properties. Perhaps the higher supplied energy to the material will increase the soft magnetic properties. It could be realized by increasing the laser beam energy or the number of laser pulses, as well as the time of laser pulse. The higher number of laser pulses, as well as the higher laser beam energy [our previous investigation (Ref 19)], leads to undesirable ablation. Changes of the laser pulses time could provide different structures, but it should be proved. 


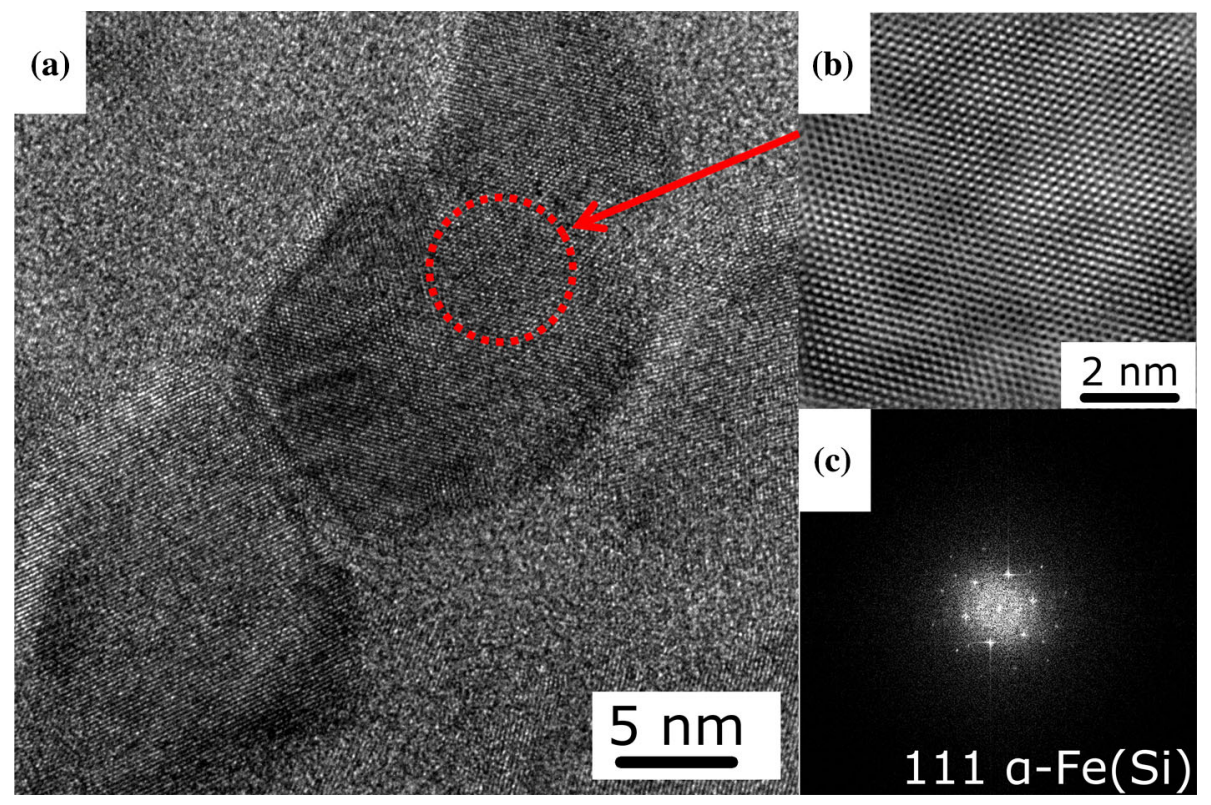

Fig. 10 HRTEM images of FeCuNbSiB annealed sample at $873 \mathrm{~K}$ : (a)—HRTEM image, (b)—magnification of selected area, (c)—FFT from 9a image
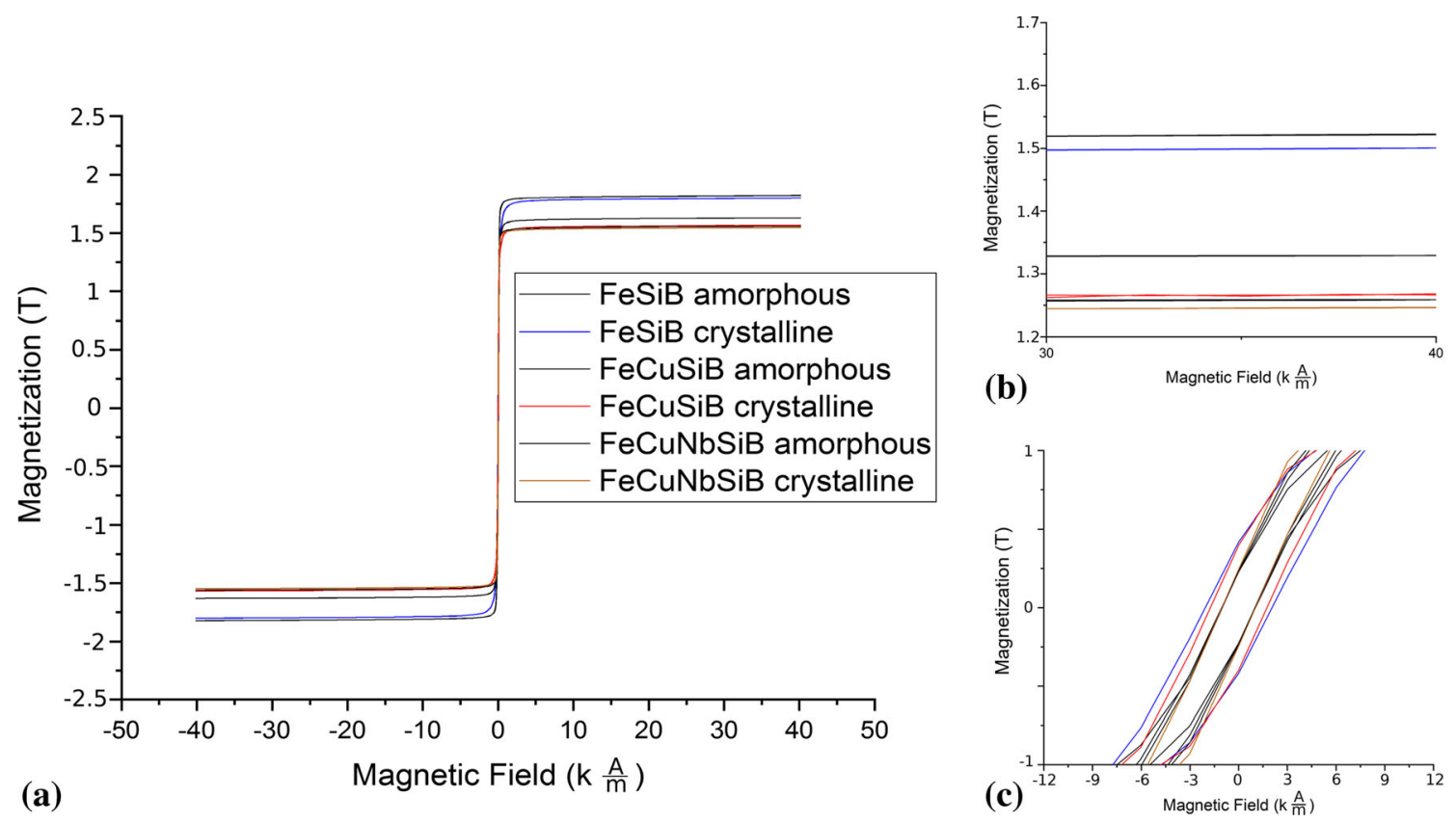

Fig. 11 Magnetic hysteresis loops of amorphous and crystalline materials: (a) - full view, (b) - magnification of saturation magnetization area, (c)-magnification of coercivity area 

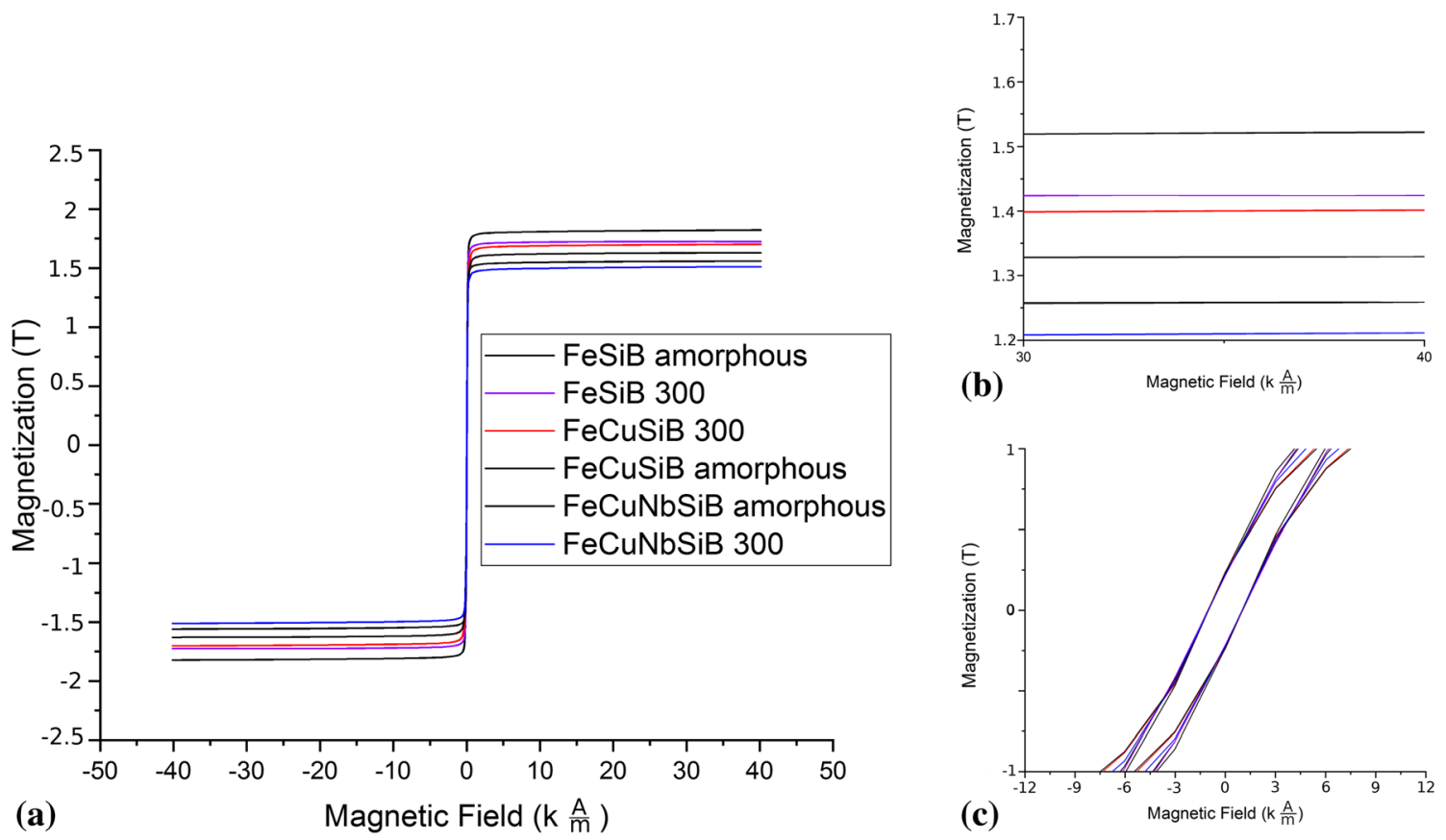

Fig. 12 Magnetic hysteresis loops of amorphous and laser-heated material with $120 \mathrm{~mJ}$ energy and 300 laser pulses: (a) - full view, (b) - magnification of saturation magnetization area, (c) - magnification of coercivity area

\section{Acknowledgment}

The authors would like to acknowledge financial support from the National Science Centre $(\mathrm{NCN})$ of Poland (Contract Number: OPUS 10, UMO-2015/19/B/ST8/01070) and The National Centre for Research and Development (Contract Number: POWR.03.05.00-00-z307/17).

\section{Open Access}

This article is licensed under a Creative Commons Attribution 4.0 International License, which permits use, sharing, adaptation, distribution and reproduction in any medium or format, as long as you give appropriate credit to the original author(s) and the source, provide a link to the Creative Commons licence, and indicate if changes were made. The images or other third party material in this article are included in the article's Creative Commons licence, unless indicated otherwise in a credit line to the material. If material is not included in the article's Creative Commons licence and your intended use is not permitted by statutory regulation or exceeds the permitted use, you will need to obtain permission directly from the copyright holder. To view a copy of this licence, visit http://creativecommons.org/licenses/by/4.0/.

\section{References}

1. Y. Yoshizawa, S. Oguma, and K. Yamauchi, New Fe-Based Soft Magnetic Alloys Composed of Ultrafine Grain Structure, J. Appl. Phys., 1988, 64(10), p 6044-6046

2. G. Herzer, Chapter 3 Nanocrystalline Soft Magnetic Alloys, in Handbook of Magnetic Materials, vol 10, ed. by K.H.J. Buschow (Elsevier Science, North Holland, 1997), p 415-462

3. T. Kulik, Nanocrystallization of Metallic Glasses, J. Non Cryst. Solids, 2001, 287(1-3), p 145-161
4. T. Kulik, J. Ferenc, and M. Kowalczyk, Temperature of Nanocrystallisation of Magnetically Soft Alloys for High-Temperature Applications, J. Mater. Process. Technol., 2005, 162-163, p 215-219

5. J. Rasek, J. Lelątko, P. Kwapuliński, G. Badura, L. Pajak, Z. Stokłosa, and G. Haneczok, Crystallization and Optimization of Soft Magnetic Properties Effect in $\mathrm{FeSiB}, \mathrm{FeNbSiB}, \mathrm{FeCuNbSiB}, \mathrm{FeCuZrCoSiB}$ Amorphous Alloys, Solid State Phenom., 2010, 163, p 225-228

6. Y. Yoshizawa, K. Yamauchi, and S. Oguma, Fe-Base Soft Magnetic Alloy and Method of Producing Same, Fe-Base Soft Magnetic Alloy and Method of Producing Same, 1988;0271657

7. H.R. Lashgari, J.M. Cadogan, D. Chu, and S. Li, The Effect of Heat Treatment and Cyclic Loading on Nanoindentation Behaviour of $\mathrm{FeSiB}$ Amorphous Alloy, Mater. Des., 2016, 92, p 919-931

8. L. Voropaeva, A. Serebryakov, N. Novokhatskaya, Y. Levin, and G. Abrosimova, Rapid Crystallization of Amorphous Alloys: FeSiB Based Alloys, Scr. Metall. Mater., 1992, 27(10), p 1385-1388

9. X.Z. Fan, X.W. He, R.K. Nutor, R.M. Pan, J.J. Zheng, H.Q. Ye, F.M. Wu, J.Z. Jiang, and Y.Z. Fang, Effect of Stress on Crystallization Behavior in a Fe-Based Amorphous Ribbon: An In Situ Synchrotron Radiation X-Ray Diffraction Study, J. Magn. Magn. Mater., 2019, 469, p 349-353

10. T. Jagielinski, Flash Annealing of Amorphous Alloys, IEEE Trans. Magn., 1983, 19(5), p 1925-1927

11. A. Sypień, J. Kusiński, G.J. Kusiński, and E.C. Nelson, TEM Studies of the FeSiB Amorphous Alloy Nanocrystallized by Means of Nd:YAG-Pulsed Laser Heating, Mater. Chem. Phys., 2003, 81, p 390-392

12. Y. Wu, K. Peng, L. Tang, and W. Zhang, Crystallization Mechanism of $\mathrm{Fe}_{78} \mathrm{Si}_{13} \mathrm{~B}_{9}$ Amorphous Alloy Induced by Ion Bombardment, Intermetallics, 2017, 91, p 65-69

13. S. Katakam, A. Devaraj, M. Bowden, S. Santhanakrishnan, C. Smith, R.V. Ramanujan, T. Suntharampillai, R. Banerjee, and N.B. Dahotre, Laser Assisted Crystallization of Ferromagnetic Amorphous Ribbons: A Multimodal Characterization and Thermal Model Study, J. Appl. Phys., 2013, 114(18), p 184901

14. W. Pakieła, T. Tański, Z. Brytan, and K. Labisz, The Influence of Laser Alloying on the Structure and Mechanical Properties of $\mathrm{AlMg}_{5} \mathrm{Si}_{2} \mathrm{Mn}$ Surface Layers, Appl. Phys. A Mater. Sci. Process., 2016, 122(4), p 1-9

15. L. Parellada-Monreal, I. Castro-Hurtado, M. Martínez-Calderón, A. Rodriguez, S.M. Olaizola, D. Gamarra, J. Lozano, and G.G. Mandayo, Study of Sputtered $\mathrm{ZnO}$ Modified by Direct Laser Interference 
Patterning: Structural Characterization and Temperature Simulation, Appl. Surf. Sci., 2018, 441, p 331-340

16. J. Marczak, A. Rycyk, A. Sarzyński, M. Strzelec, J. Kusiński, and R. Major, Direct Laser Manufacturing of 1D and 2D Micro- and Submicro-Scale Periodic Structures, Proc. Spie., 2013, 8703, p 1-12

17. Y. Zabila, M. Perzanowski, A. Dobrowolska, M. Kąc, A. Polit, and M. Marszałek, Direct Laser Interference Patterning: Theory and Application, Acta Phys. Pol., A, 2009, 115(2), p 591-593

18. J. Kusinski, O. Czyz, A. Radziszewska, J. Morgiel, C. Kapusta, R Ostrowski, M. Strzelec, and K. Czyz, Microstructure and Properties of Laser Interference Crystallized Amorphous FeSiB Ribbon, Int. J. Mater. Res., 2019, 110(1), p 11-17

19. O. Czyż, J. Kusiński, A. Radziszewska, R. Ostrowski, J. Morgiel, J. Kanak, and M. Kac, Modification of the Structure and Properties of FeSiB Amorphous Ribbon by Interference Pulsed Laser Heating, Arch. Metall. Mater, 2018, 63(4), p 2001-2007

20. R.C. Budhani, T.C. Goel, and K.L. Chopra, Melt-Spinning Technique for Preparation of Metallic Glasses, Bull. Mater. Sci., 1982, 4(5), p 549-561

21. R. Ostrowski, J. Kusiński, K. Czyż, A. Rycyk, A. Sarzyński, W. Skrzeczanowski, M. Strzelec, and O. Czyż, Preliminary Tests of Nanocrystallization of Amorphous Magnetic Ribbons under the Influence of
Periodical, Interference Laser Micromachining, Photonics Lett. Pol., 2017, 9(3), p 91-93

22. K. Suzuki and G. Herzer, Soft Magnetic Nanostructures and Applications, in Advanced Magnetic Nanostructures, ed. by D.J. Sellmyer, R. Skomski (Springer US, 2006) p 365-401

23. H.R. Lashgari, Z. Chen, X.Z. Liao, D. Chu, M. Ferry, and S. Li, Thermal Stability, Dynamic Mechanical Analysis and Nanoindentation Behavior of $\mathrm{FeSiB}(\mathrm{Cu})$ Amorphous Alloys, Mater. Sci. Eng., A, 2015, 626, p 480-499

24. A. Inoue, B. Shen, and T. Ohsuna, Soft Magnetic Properties of Nanocystalline Fe-Si-B-Nb-Cu Rod Alloys Obtained by Crystallization of Cast Amorphous Phase, Mater. Trans., 2002, 43(9), p 2337-2341

25. W. Jia, Z. Peng, Z. Wang, X. Ni, and C.Y. Wang, The Effect of Femtosecond Laser Micromachining on the Surface Characteristics and Subsurface Microstructure of Amorphous FeCuNbSiB Alloy, Appl. Surf. Sci., 2006, 253(3), p 1299-1303

Publisher's Note Springer Nature remains neutral with regard to jurisdictional claims in published maps and institutional affiliations. 